\title{
Monetary transmission mechanism in Turkey under the monetary conditions index: an alternative policy rule
}

\section{Vuslat Us}

To cite this article: Vuslat Us (2004) Monetary transmission mechanism in Turkey under the monetary conditions index: an alternative policy rule, Applied Economics, 36:9, 967-976, DOI: 10.1080/0003684042000233195

To link to this article: http://dx.doi.org/10.1080/0003684042000233195

Published online: 22 Aug 2006.

Submit your article to this journal ऍ

Џلll Article views: 132

Q View related articles $\sqsubset$

Citing articles: 3 View citing articles $\square$ 


\title{
Monetary transmission mechanism in Turkey under the monetary conditions index: an alternative policy rule
}

\author{
VUSLAT US \\ The Central Bank of the Republic of Turkey, Research Department, Ankara, Turkey \\ and Bilkent University, Ankara, Turkey \\ E-mail:vuslat.us@tcmb.gov.tr
}

This study analyses monetary transmission mechanism in Turkey using a small structural macroeconomic model. The core equations of the model consist of aggregate demand, wage-price setting, uncovered interest rate parity, foreign sector and a monetary policy rule. The aim of the paper is to analyse the disinflation path, the output gap, the output level, the exchange rate and the interest rate, and also the output-inflation variance frontier of the economy under various scenarios. The first scenario assumes that a standard Taylor rule is implemented as the policy rule. In the alternative scenario, instead of the standard Taylor rule, the MCI, Monetary Conditions Index - combination of the changes in the short-term real interest rate and in the real effective exchange rate in a single variable - is used as a policy instrument. The results indicate that the economy stabilizes much more quickly and shows significantly less volatility under this new setting. Therefore, the paper concludes that the policymakers should consider using MCI as an instrument when conducting monetary policy.

\section{INTRODUCTION}

Central Banks have only limited information about the structural relationships in the economy, and consequently, they have imperfect control over prices and ultimate target variables such as inflation target. In order to assess the current economic condition, therefore, central banks need leading indicators, variables that contain information on the future path of the target variables. They also need policy indicators - variables for the assessment of the impact of a prospective monetary policy.

Two monetary policy indicators that have received a vast amount of attention are the Taylor interest rate and the MCI, the Monetary Conditions Index. Taylor (1993) shows that the short-term interest rate is a function of the inflationary developments and cyclical changes in the economy. Hence, the author formulates the 'Taylor rule' according to which, the Central Bank raises interest rate if inflation and output exceed the targeted values, and similarly, Central Bank lowers interest rate if inflation and output are below the targeted values. The Monetary Conditions Index, on the other hand, is an index combined by the changes in the short-term real interest rate and in the real effective exchange rate. The purpose of constructing such an index is to take account of the role of both of the variables - the interest rate and the exchange rate - in the conduct of monetary policy, and hence, the monetary policy transmission process.

The paper proceeds as follows. In the next section, a comparative analysis of the Taylor interest rate and the MCI is presented. The following section describes a theoretical MCI model. The next section gives the key equations of the structural model and the underlying factors determining the model dynamics are discussed. The 
succeeding section is on simulations where the impulse responses of the economy to various shocks as well as the output-inflation variance frontier of the economy are analysed. Finally, the last section concludes this paper.

\section{A QUICK GLANCE AT THE TAYLOR RULE AND THE MCI}

Taylor (1993) defines a policy rule as 'a contingency plan that lasts forever unless there is an explicit cancellation clause'. He states that among the many alternatives, there exists consensus on the performance of only some of the policy rules. For example, measured in output and price variability, as discussed by the author, the policy rules that focus on the exchange rate or money supply do not show a good performance as much as policies that focus on the price level and real output directly. In other words, monetary policy rules perform well if the rule states that an excessive price rise and an overutilization of production capacity should be counteracted by a higher short-term interest rate and vice versa. Accordingly, Taylor (1993) proposes a representative policy rule such that

$$
i=\alpha+0.5\left(\pi-\pi^{*}\right)+0.5\left(y-y^{*}\right)
$$

where, $i$ is the short-term nominal interest rate, $\left(\pi-\pi^{*}\right)$ is the gap between actual inflation rate and the inflation target, and similarly $\left(y-y^{*}\right)$ is the gap between actual output and the potential output. When both inflation and output are at their steady-state values, the interest rate also reaches its long-run equilibrium value, $\alpha$. By assigning equal weights of 0.5 to $\left(\pi-\pi^{*}\right)$ and $\left(y-y^{*}\right)$, the author thus gives equal significance to both economic growth and maintaining price stability in the conduct of monetary policy. Taylor (1993) finally concludes that the above rule has empirically good performance across G-7 countries, and is also robust to structural changes.

Despite its simplicity, using Taylor rule as a policy rule raises some theoretical as well as empirical problems. First of all, the equal weights assigned to the inflation gap and the output gap, $\left(\pi-\pi^{*}\right)$ and $\left(y-y^{*}\right)$, may not truly describe the structure of every economy. Therefore, these coefficients should in fact be econometrically estimated. ${ }^{1}$ Furthermore, the choice of the price index significantly alters the result when calculating the inflation rate, since, even though price indices may follow a similar path in most cases, they may also behave quite differently in some other cases, especially due to excessive exchange rate movements. Another practical issue is raised by the calculation of the output gap, which, depending on the method for calculating the potential output, may produce quite differences. $^{2}$

The assumption of constant long-run equilibrium value for the interest rate is another weakness of the Taylor rule. As the economy changes so does the long-run equilibrium value of the interest rate. In other words, as the factors affecting the interest rates like credibility of the central bank or the uncertainty pertaining to the economy or returns on other assets change, the interest rate may settle at a different plateau. Hence, the assumption of 'constant long-run equilibrium value for the interest rate' is invalidated. Another shortcoming of the standard Taylor rule is rather than taking into account of the outlook for the prices, it only considers the effect of the current inflation on interest rates. However, neglecting the role of the future prices in the policy rule only leads to systematic delays in the transmission of the effects of the current monetary policy decisions. Furthermore, adding relevant information like future prices to the Taylor rule will improve the effectiveness of the monetary policy. Finally, the Taylor rule also lacks the ability to differentiate once-and-for-all changes in the output level or in the inflation rate from more permanent changes. In either case, it calls for a need to change the level of the interest rate, where in fact, the economy could have stabilized by itself. In order to alleviate such misdirection therefore, the policymakers should either analyse the individual determinants of the price level changes or base their inflation measure on 'core inflation rate' instead of the CPI inflation. ${ }^{3}$

Even though, as a near-rule-of-thumb, many researchers incorporate Taylor rule into their models, some have advocated the use of alternative rules (Svensson, 1999, 2000; Ball, 1997, 1999, 2000; Batini and Haldane, 1998; Markovic, 2001; Clarida et al., 1997; Clarida and Gertler, 1996). One such alternative is the use of the MCI, which includes the effect of the exchange rate movements on the monetary policy decisions by constructing an index series, where the deviations of the exchange rate and the interest rate from their long-run equilibrium values are combined. The purpose of computing an MCI is to combine interest rate and exchange rate movements in a consistent manner

\footnotetext{
${ }^{1}$ Kesriyeli and Yalçın (1998) econometrically test the Taylor rule for Turkey for the period 1987-1998. The authors, by using Two Stage Least Square method, find the coefficient of the output gap and the inflation gap in the monetary policy reaction function for Turkey to be equal to 6.92 and 0.8 , respectively. Given the remarkably higher magnitudes of the coefficients than suggested by the Taylor rule, the authors conclude that Taylor rule does not perform well in economies like Turkey, where high and persistent inflation with unstable economic growth is dominant.

${ }^{2}$ The common methods for calculating potential output are by log-linear transformation of output level, or using a filtered output series such as Hodrick-Prescott or by simply estimating a production function. However, all the above methods may produce major differences that are then reflected directly in the level and the behaviour of the Taylor interest rate.

${ }^{3}$ Core inflation is assumed to filter out the transitory changes in prices.
} 
and thus express the change in the underlying monetary conditions in a single variable.

In its original form, as developed by the Bank of Canada, the MCI is, at a given time $t$, the weighted sum of the relative change in the effective exchange rate and the absolute change in the short-term real rate of interest compared with a base period:

$$
M C I_{t}=w_{e}\left[\frac{e r_{t}}{e r_{0}}-1\right]+w_{r}\left[\frac{r_{t}}{r_{0}}\right]
$$

where, $w_{e}$ is the weight assigned to the changes in exchange rate; $w_{r}$ is the weight assigned to the changes in interest rate; $e r_{t}$ is the weighted real external value at $t ; e r_{0}$ is the weighted real external value in base period; $r_{t}$ is the shortterm real rate of interest at $t$, and $r_{0}$ is the short-term real rate of interest in base period. The weights $w_{e}$ and $w_{r}$ reflect the relative effects of the respective MCI component on aggregate demand. In other words, the above weights are proportional to the effects of the exchange rate and interest rate on aggregate spending.

The reason behind the increasing popularity of the use of MCI as an operational target across countries such as Canada, Sweden, Norway, New Zealand, and by outside monetary analysts in Eurosystem is its ability to capture, in a single variable, quantifying information about the stance of the monetary policy (Freedman, 1995; Gerlach and Smets, 2000). In an open economy, monetary policy influences spending through both the interest rate and the exchange rate. The overall change in spending therefore depends on the changes in these two variables, with the magnitude given by the IS coefficients. More specifically, the rise in interest rates or exchange rates causes the economy to slow down and thus alleviates inflationary pressures. However, a fall in interest rates or exchange rates fuels the economy and leads to higher inflationary pressures. Therefore by constructing an MCI, the effects of both the exchange rate and the interest rate are taken into consideration.

\section{A THEORETICAL MODEL ON MCI}

Following the discussion on Taylor rule and the MCI, this section will describe a theoretical model on MCI. Ball $(1999,2000)$ proposes a simple model that captures the key interactions of macroeconomic variables and also offers a new policy rule that includes MCI. The model consists of three equations such that:

$$
\begin{aligned}
y & =\lambda y_{-1}-\beta r_{-1}-\delta e_{-1}+\varepsilon \\
\pi & =\pi_{-1}+\alpha y_{-1}-\gamma\left(e_{-1}-e_{-2}\right)+\eta \\
e & =\theta r+v
\end{aligned}
$$

where $y$ is output, $\pi$ is inflation, $r$ is the real interest rate, $e$ is the real exchange rate (a higher $e$ means appreciation) and $\varepsilon, \eta$, and $v$ are shocks. All variables are defined as deviations from equilibrium values, and all coefficients are positive.

Equation 3 is an open economy IS curve, where output depends positively on its lagged value, and negatively on interest rate and exchange rate. Equation 4 is an open economy, accelerationist Phillips curve where, change in inflation depends on output and the change in the real exchange rate, which affects the inflation through import prices. Equation 5 posits a positive relation between interest rates and exchange rates. In an open economy with capital mobility, higher interest rates attract capital, and thus the capital inflow leads to the appreciation of the domestic currency. Clearly, the error terms capture the effects of other variables that are not defined in this model.

The central bank chooses the interest rate $r$. Conducting monetary policy affects inflation through two channels. A monetary contraction reduces output and thus inflation through the Phillips curve, and it also causes an appreciation that reduces inflation directly. The first channel takes two periods to work, whereas the second channel takes only one period: After the appreciation of the currency due to tightening of the monetary policy, inflation drops in the following period. Therefore, because of the exchange rate pass-through, there is a direct link between policy and inflation rather than the more indirect link between interest rate-exchange rate to output and output to inflation.

After substituting Equation 5 into Equation 3 and shifting the time subscripts one period forward, then:

$$
\begin{aligned}
& y_{+1}=-(\beta / \theta+\delta) e+\lambda y+e_{+1}+(\beta / \theta) v \\
& \pi_{+1}=\pi+\alpha y-\gamma\left(e-e_{-1}\right)+\eta_{+1}
\end{aligned}
$$

Assume that a policymaker chooses the current $e$. Then, the state variables of the model can be defined by two expressions corresponding to terms on the right-hand side of Equations 6 and 7: $\lambda y+(\beta / \theta) \nu$, and $\pi+\alpha y+\gamma e_{-1}$. Since the model is linear quadratic, the optimal rule in two variables is:

$$
e=m[\lambda y+(\beta / \theta) \nu]+n\left[\pi+\alpha y+\gamma e_{-1}\right]
$$

where, $m$ and $n$ are constants. Plugging Equation 5, and rearranging:

$$
w r+(1-w) e=a y+b\left(\pi+\gamma e_{-1}\right)
$$

where, $\quad w=m \beta \theta /(\theta-m \beta+m \beta \theta), \quad a=\theta(m \lambda+n \alpha) /(\theta-m \beta+$ $m \beta \theta), b=n \theta /(\theta-m \beta+m \beta \theta)$. Thus the optimal policy rule as a rule for an average of $r$ and $e$ is obtained. Thus, the left-hand side variable of the rule is no longer the interest rate like in the standard Taylor rule, but the weighted average of interest rate and exchange rate, the MCI. Equation 9 can be rewritten as

$$
\left.r=(a / w) y+(b / w)\left(\pi+\gamma e_{-1}\right)-((1-w) / w)\right) e
$$

Equation 10 looks more like a Taylor rule. However, according to the above equation, the policymakers, in addi- 
tion to adjusting the interest rate in response to changes in inflation and output, also adjust the interest rate in response to changes in exchange rates. Equation 10 therefore, enables the advocates of Taylor rule and advocates of MCI to reach a consensus.

\section{THE KEY EQUATIONS OF THE MACROECONOMIC MODEL}

After the detailed analysis of a theoretical MCI model in the previous section, this section describes the key equations of the macroeconomic model developed for simulation purposes. The model is given by the following system of Equations 11-23:

IS Curve:

$\operatorname{ygap}_{t}=\alpha_{1} \operatorname{ygap}_{t-1}+\alpha_{2} \operatorname{ygap}_{t-2}+\alpha_{3} i r_{t}+\alpha_{4}\left(e r_{t}-e r_{t-1}\right)+\varepsilon_{1 t}$

Wage-Price setting:

$$
\Delta w_{t}=\beta_{1} w_{t-1}-\beta_{1}\left(y_{t-1}-l_{t-1}+p c_{t-1}\right)+\varepsilon_{2 t}
$$

Phillips Curve:

$$
\begin{aligned}
\pi_{t}= & E_{t} \pi_{t+1}+\lambda_{1} p_{t-1}^{m}+\lambda_{2}\left(w_{t-1}-y_{t-1}+l_{t-1}\right) \\
& -\left(\lambda_{1}+\lambda_{2}\right) p c_{t-1}+\lambda_{3} \Delta p_{t}^{m}+\varepsilon_{3 t}
\end{aligned}
$$

Uncovered interest rate parity condition:

$$
e r_{t}=i r f_{t}-i r_{t}+e r_{t+1}
$$

Foreign sector:

$$
\begin{aligned}
y_{t}^{*} & =\psi y_{t-1}^{*} \\
\pi_{t}^{*} & =\psi \pi_{t-1}^{*} \\
i^{*} & =\xi_{1} \pi_{t}^{*}+\xi_{2} y_{t}^{*}
\end{aligned}
$$

Production function:

$$
\begin{aligned}
y & =\theta k+(1-\theta) l+y g a p+\varepsilon_{4 t} \\
\varepsilon_{4 t} & =\delta \varepsilon_{4 t-1}
\end{aligned}
$$

Monetary Conditions Index:

$$
M C I=w i r-(1-w) r e r
$$

Expectations formation:

$$
E_{t} \pi_{t+1}=\phi \pi_{t-1}+(1-\phi) \pi_{t+1}
$$

Monetary policy rule:

Taylor Rule:

$$
i=\pi_{t+1}+\mu_{1}(\pi-\operatorname{targ} e t)+\mu_{2} y g a p
$$

MCI Rule:

$$
i=\pi_{t+1}+(1 / w)\left((1-w) r e r+\mu_{1}(\pi-t \arg e t)+\mu_{2}\right. \text { ygap }
$$

where, all variables, except interest rates are expressed in logs. The variable $y$ is the output level and ygap is the difference between level of output and potential output. $k, w$ and $l$ denote capital stock, nominal wage rate and employment, respectively. $i$ and $i r$ are nominal and real domestic interest rates, and irf is the foreign real interest rate. The inflation rate and price level are represented by $\pi$ and $p c$ respectively. $\pi^{*}$ is the foreign inflation rate and $p^{m}$ is the price of imports. target is the inflation target, and er and rer denote the nominal and real exchange rate, respectively. $E_{t}$ is the mathematical expectations operator as of time $t$, and $\Delta$ is the first difference operator. All the coefficient values are presented in Table 1.

Equation 11 is the open economy IS equation, where aggregate demand depends on the lagged values of the output gap, the real interest rate and the exchange rate. The real interest rate is negatively related to the aggregate demand since a lower interest rate induces investment spending, and therefore increases the aggregate demand. Depreciation of the domestic currency, an increase in real exchange rate, fuels the economy since now domestic goods

Table 1. Model parameters

\begin{tabular}{lcl}
\hline IS curve & 1.41 & Autoregressive element \\
$\alpha_{1}$ & -0.66 & Autoregressive element \\
$\alpha_{2}$ & -0.11 & Real interest rate response \\
$\alpha_{3}$ & 0.10 & Real exchange rate response \\
$\alpha_{4}$ & & \\
Wage-setting & -0.24 & Autoregressive element \\
$\beta_{1}$ & & Unit labour productivity \\
Price-setting & 0.09 & Import price response \\
$\lambda_{1}$ & 0.11 & Unit labour cost response \\
$\lambda_{2}$ & 0.23 & Imported inflation response \\
$\lambda_{3}$ & & \\
Foreign sector & 0.8 & Autoregressive element \\
$\psi$ & 1.5 & Feedback parameter \\
$\xi_{1}$ & $0.125 \mathrm{~s}$ & Feedback parameter \\
$\xi_{2}$ & & \\
Production function & 0.465 & Marginal product of capital \\
$\theta$ & 0.96 & Autoregressive element \\
$\delta$ & & \\
Expectations formation & & \\
$\phi$ & 0.5 & Feedback parameter \\
Monetary policy rule & & \\
$\mu_{1}$ & 0.5 & Feedback parameter \\
$\mu_{2}$ & 0.125 & Feedback parameter \\
$w$ & 0.53 & Weight of real interest rate \\
\hline
\end{tabular}

\footnotetext{
${ }^{4}$ This model is originally developed by Şahinbeyoğlu (2001) and further modifications to the model were added by the CCBS/Money and Finance Group. However, some of the equations that were constructed for the purposes of the above study were commented out. Additionally, aggregate demand, wage-price setting equations were updated. Most crucially, the monetary policy rules in both alternatives are the novelties of this study.
} 
are cheaper than the foreign goods, and hence the exchange rate is positively related to the aggregate spending. Equation 12 describes wage-setting of the economy according to which the nominal wages depend on the unit labour productivity, past inflation and wages. As the labour productivity increases, current wages increase as well. The increase in past period's inflation is also transmitted to current wages through indexation. Equation 13 is the Phillips curve equation, which describes the price-setting of the economy. According to the equation, unit labour cost, inflation expectations, imported inflation, foreign price level and domestic price level affect the current inflation rate. Equation 14 is the uncovered interest parity condition that links the changes in exchange rate to interest rate differential between home and abroad. Equations 1516 describe the inflationary process and the economic growth in the foreign sector, which imply that they both grow at the same rate. Equation 17 is a standard Taylor rule according to which the foreign sector monetary policy is conducted. Equations 18-19 describe a Cobb-Douglas type of production function where a productivity shock is also included. Equation 20 defines the Monetary Conditions Index as a weighted sum of real interest rate and real exchange rate. ${ }^{5}$ Equation 21 gives the expectations formation, which implies that half of the agents in the economy are forward-looking and the other half is backward-looking. Equation 22 is a modification on standard Taylor rule where future inflation rate is also added on the right-hand side of the equation. ${ }^{6}$ Equation 23 on the other hand, is the alternative policy rule as described by the MCI rule, where the interest rate term $i$ in Equation 22 is replaced by the MCI given in Equation 21.

\section{SIMULATIONS}

This section will analyse some simulations on the model. The monetary transmission mechanism in Turkey can best be explored by simulating various shocks in the model. ${ }^{7}$ Assuming that monetary policy reaction function is described by Taylor rule, three basic experiments are conducted. In the first simulation, the impulse response functions to a monetary shock will be analysed. In the following simulation, the impulse response functions to a disinflation will be presented. Finally, in the last simulation, the impulse response functions to a productivity shock will be studied. Alternatively, same simulations will be repeated, now assuming that the central bank takes into account of the exchange rate deviations in the conduct of monetary policy, i.e., the MCI is used as a monetary policy instrument. In all alternative scenarios, in addition to analysing the behaviour of the impulse responses, the variances will also be examined. All the variables are set to zero in the baseline scenario.

\section{Simulation 1A: decrease in nominal interest rates}

The first simulation is a temporary and unanticipated one percentage point increase in the annual nominal interest rates. The shock lasts for four quarters. Therefore, $1 \%$ increase in the yearly interest rate is proxied by a $0.25 \%$ increase in the nominal interest rates on quarterly basis.

Under both alternatives, with the exception of the initial response of the nominal interest rate, the impulse response functions of output, the output gap, inflation rate, exchange rate, nominal interest rate and the real exchange rate are very similar in terms of their pattern. Yet, there are quite major differences between the two rules, such that, if the central bank follows Taylor rule, there is much more volatility as evident by the large swings of the impulse response functions of all the variables in the question. Furthermore, it takes much longer for the economy to stabilize under this rule: Under the Taylor rule, it takes about 33 quarters for the economy to stabilize, whereas, assuming MCI rule, this period reduces to 17 quarters. In addition to this significant difference between two alternatives in terms of the time to stabilization, there is also considerably smaller decline in output and output gap under the MCI rule (Fig. 1).

The variances of output, the output gap, inflation and the exchange rate also prove the relatively lesser volatility of the economy under the MCI rule. The variances of output and the output gap are almost zero under the MCI rule, whereas, under the Taylor rule, the variances level at about 0.06 after a continuous increase for 17 quarters. The variance of inflation under MCI rule is about half of the variance of the inflation under the Taylor rule, yet, having similar patterns. The variance of the exchange rate is considerably lower under MCI rule than in the Taylor rule, again following a similar pattern. In both alternatives, after following the shock, the variances of inflation and the

\footnotetext{
${ }^{5}$ Even though the MCI is the combination of the weighted averages of the deviations of the real exchange rate and the real interest rate from their long-run equilibrium values, MCI in the above model is the weighted average of the real exchange rate and the real interest rate, since the model assumes the long-run equilibrium values of the real exchange rate and real interest rate to be equal to zero. Furthermore, instead of having a positive weight, real exchange rate has a negative weight since in the context of the Turkish economy, a lower level of the real exchange rate corresponds to appreciation of the domestic currency.

${ }^{6}$ When rearranged, it can be seen that Equation 22 boils down a policy rule where real interest rate is used a policy instrument.

${ }^{7}$ The model is solved using the Winsolve package and Fair-Taylor solution algorithm.
} 

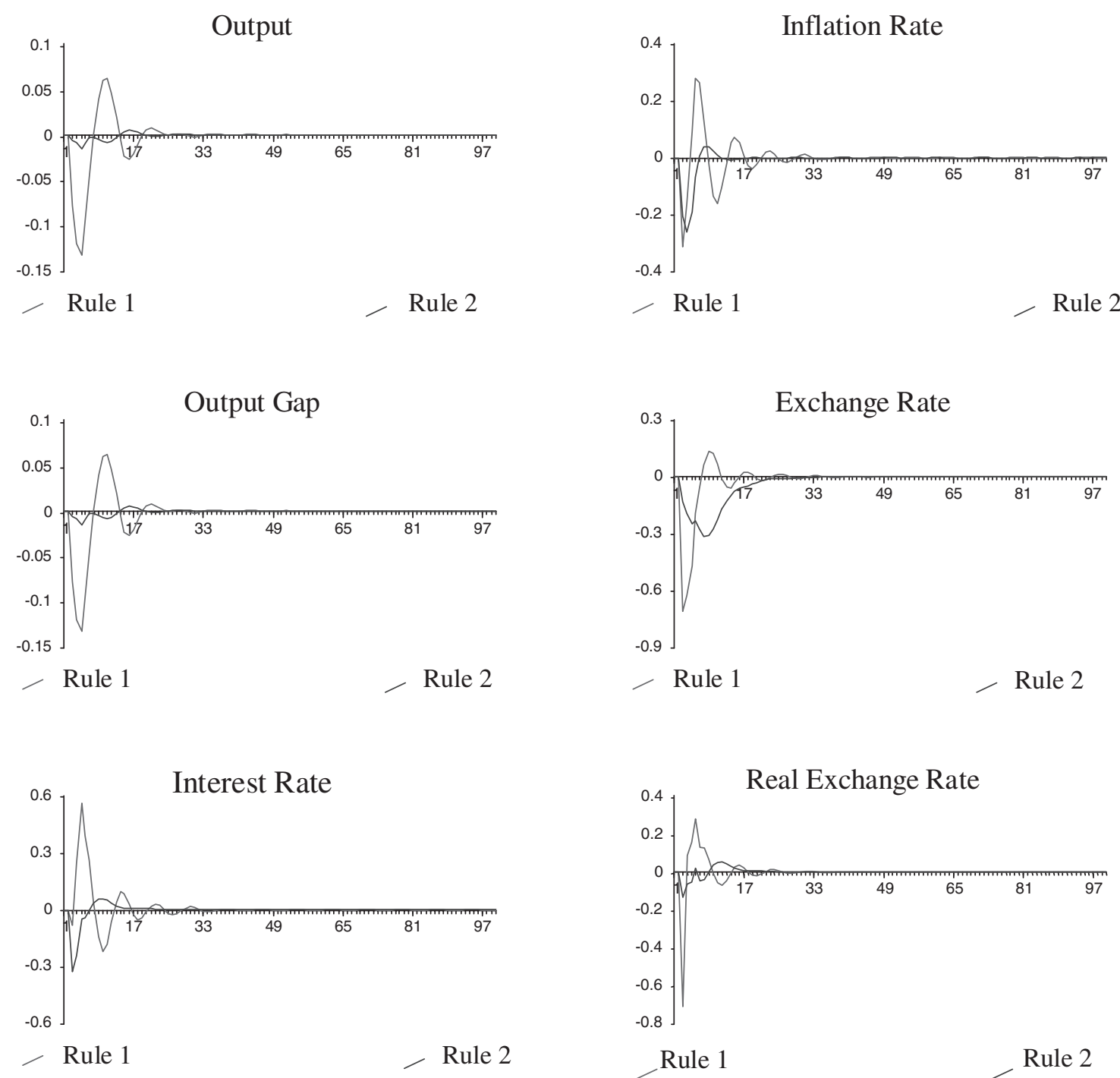

Fig. 1. Impulse responses to a temporary and unanticipated $1 \%$ increase in nominal interest rate

exchange rate reach a higher plateau, but in the Taylor rule, this level is significantly higher (Fig. 2).

\section{Simulation 2A: Decrease in inflation target}

The second simulation is a temporary and unanticipated one percentage point decrease in the annual inflation target. The length of the shock is four quarters; therefore, $1 \%$ decrease in the yearly inflation target is proxied by a $0.25 \%$ decrease in the quarterly inflation target.

As in the previous simulation, except the initial response of the nominal interest rate, the impulse response functions of output, the output gap, inflation rate, exchange rate, nominal interest rate and the real exchange rate are very similar in terms of their pattern under both alternatives. Major differences continue to exist between the two rules in this simulation as well. Assuming that the central bank follows the Taylor rule, there is much more volatility as apparent by the big waves of the impulse response functions of all the variables at issue. However, with the exception of the response of the inflation, the differences between two alternatives in terms of the time to stabilization are not so evident this time. In both alternatives, it takes about equal amount of time until all the variables in question stabilize. However, inflation under the MCI rule shows a quicker stabilization. Like in the previous exercise, the impulse responses of output and the output gap exhibit drastic differences between two alternative rules (Fig. 3).

Unlike the previous simulation, even though the variances of output, the output gap and the exchange rate are considerably lower under MCI rule, the variance of the inflation settles at a higher level under the MCI rule. This result is surprising given the relatively less wavy pattern of the impulse response function of the inflation under the MCI rule. Still, the difference is not so prominent; it corresponds to only about 5 percentage points (Fig. 4). 

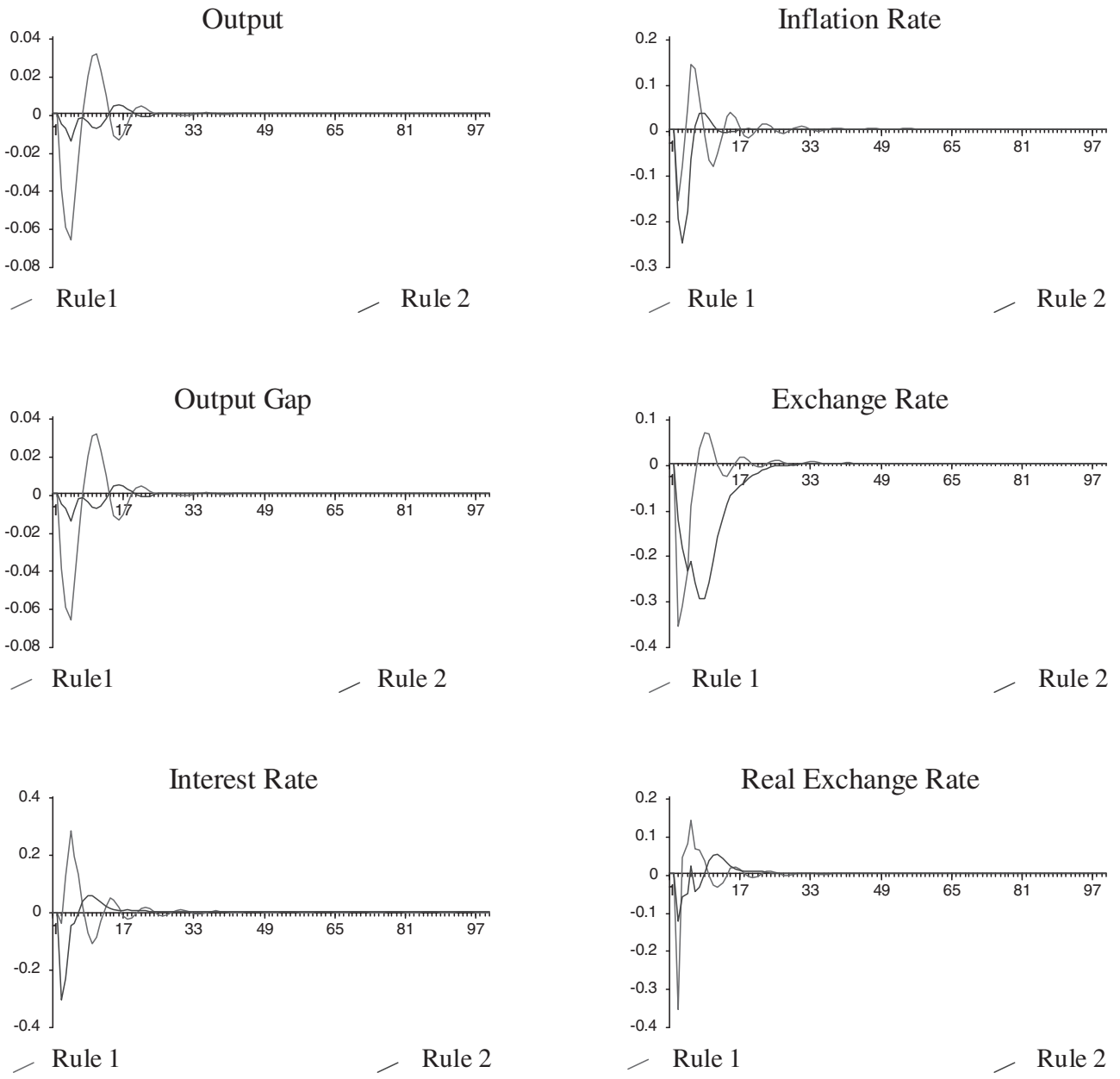

Fig. 2. Impulse responses to a temporary and unanticipated 1\% decrease in inflation target

\section{Simulation 3A: Decrease in the productivity}

The final simulation is a temporary and unanticipated onepercentage point decrease in the annual productivity. The shock lasts for four quarters; and like in previous simulations, $1 \%$ decrease in the productivity is proxied by a $0.25 \%$ decrease in the quarterly productivity.

Unlike the previous simulations, except the impulse response of output, the impulse response functions of the other variables differ remarkably between alternative rules. Both in terms of pattern and volatility of the response functions, there are noticeable differences between the two alternatives. In the first alternative where the central bank follows Taylor rule, there is seemingly greater volatility, whereas under the second alternative, all the variables follow a smoother pattern towards stabilization. The time to stabilization is significantly different between two alternatives. While, it takes about ten quarters for inflation to stabilize under the MCI rule, it may take up to 33 quarters for the inflation to stabilize under the first alternative. However, output behaves quite similarly in both alternatives. Yet, under the MCI rule, there is a slightly lesser initial drop in output than under the Taylor rule (Fig. 5).
The graphs of the variances of output, the output gap, inflation and interest rate have similar shapes under both rules. Like the impulse response function, the variance of the output under the two alternatives is nearly the same. The variance of the inflation under the MCI rule is almost zero, whereas, it settles at a higher plateau under the Taylor rule. The variances of the output gap and the exchange rate are higher in Taylor rule than in the MCI rule (Fig. 6).

\section{CONCLUSION}

This paper has analysed the choice of monetary regimes with regard to two monetary policy indicators: the Taylor interest rate and the Monetary Conditions Index. Despite its simplicity and its empirically good performance in some countries as in G-7, the Taylor rule has also some shortcomings since it totally ignores the effect of monetary policy on the exchange rate, and thus denies the exchange rate pass-through. However, simply overlooking the link between monetary policy and exchange rate only results in missed opportunities on the side of policymakers to adjust interest rates in order to offset the effects of 

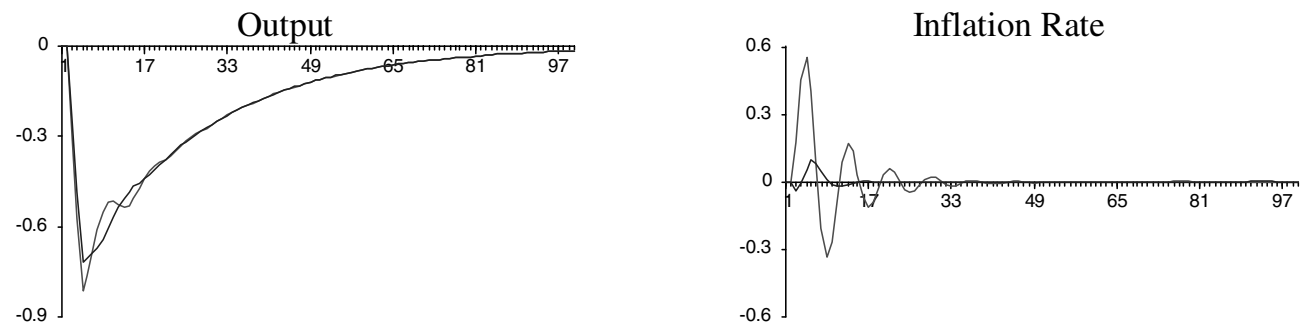

- Rule 1

_ Rule 2

- Rule 1

Rule 2
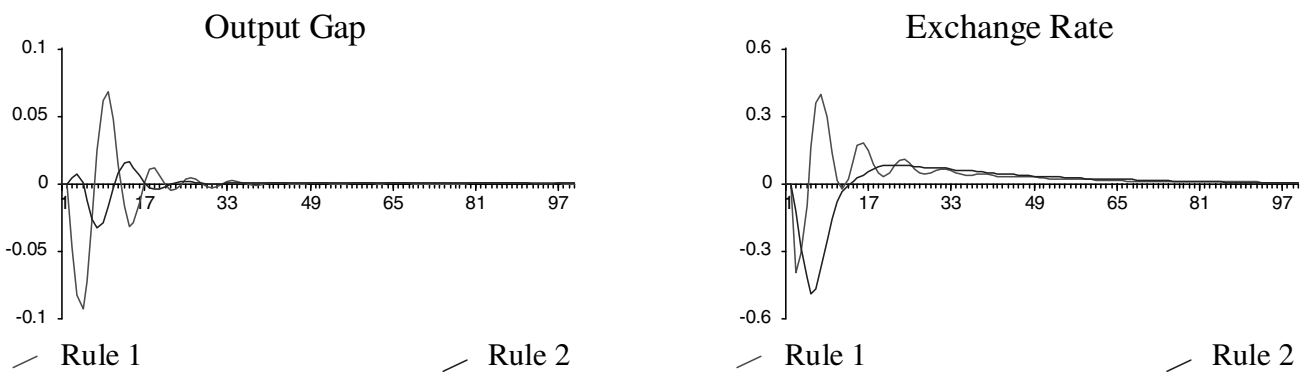

- Rule 1

- Rule 2

Rule 1

Rule 2
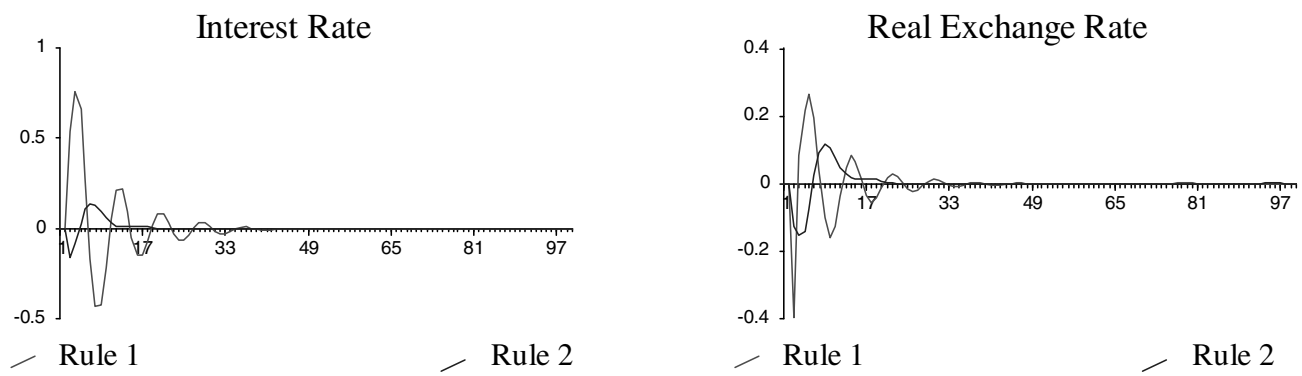

Fig. 3. Impulse responses to a temporary and unanticipated $1 \%$ decrease in productivity
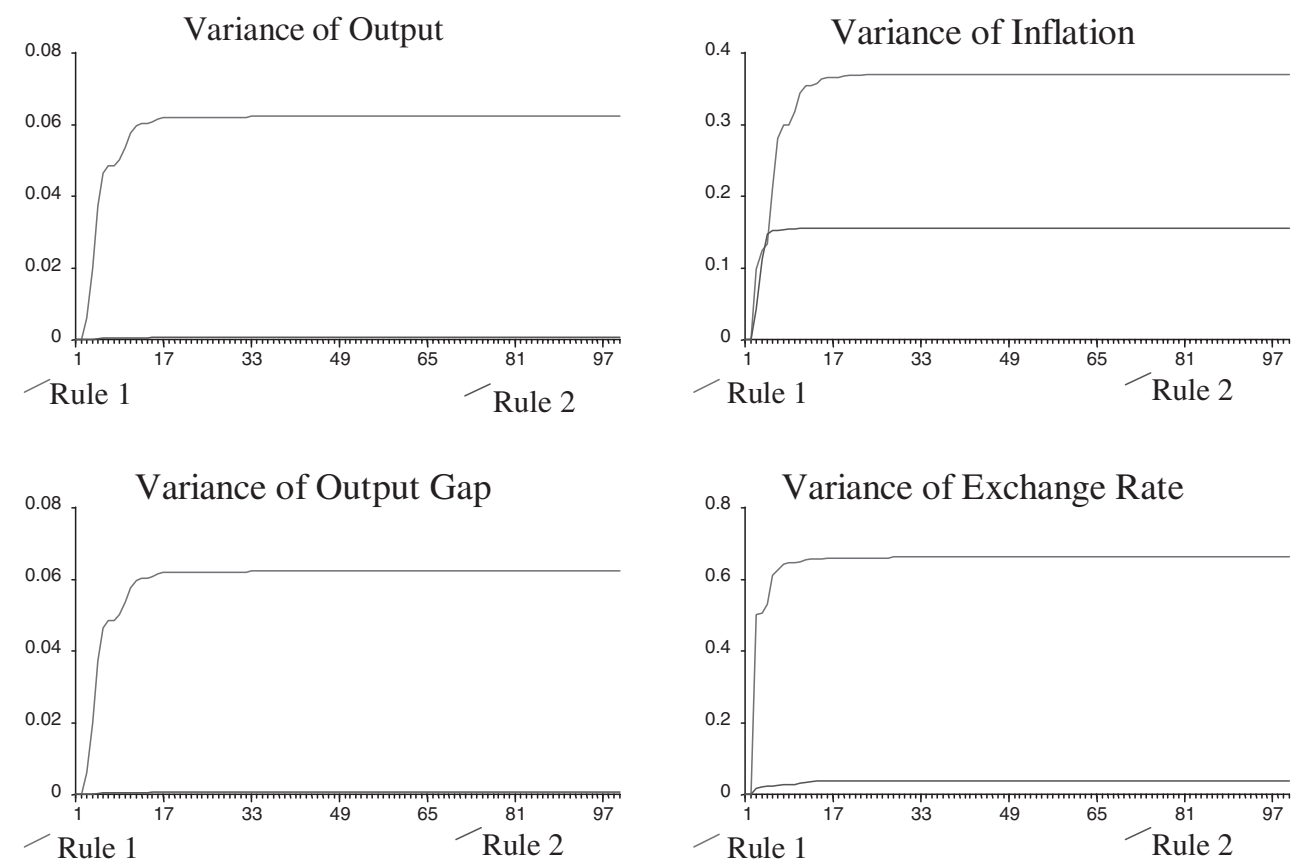

Fig. 4. Variances in response to a temporary and unanticipated $1 \%$ increase in nominal interest rate 

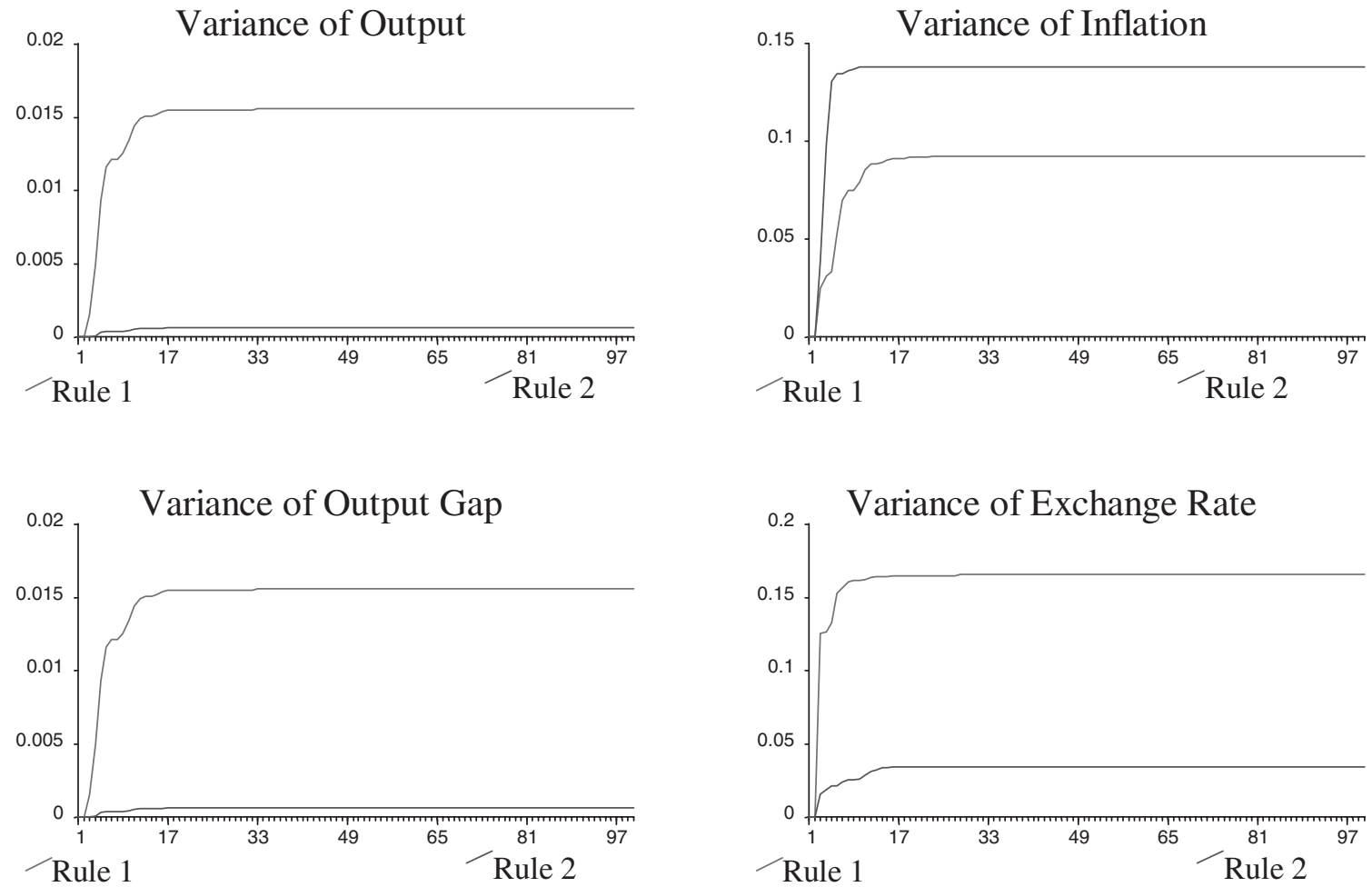

Fig. 5. Variances in response to a temporary and unanticipated 1\% decrease in inflation target
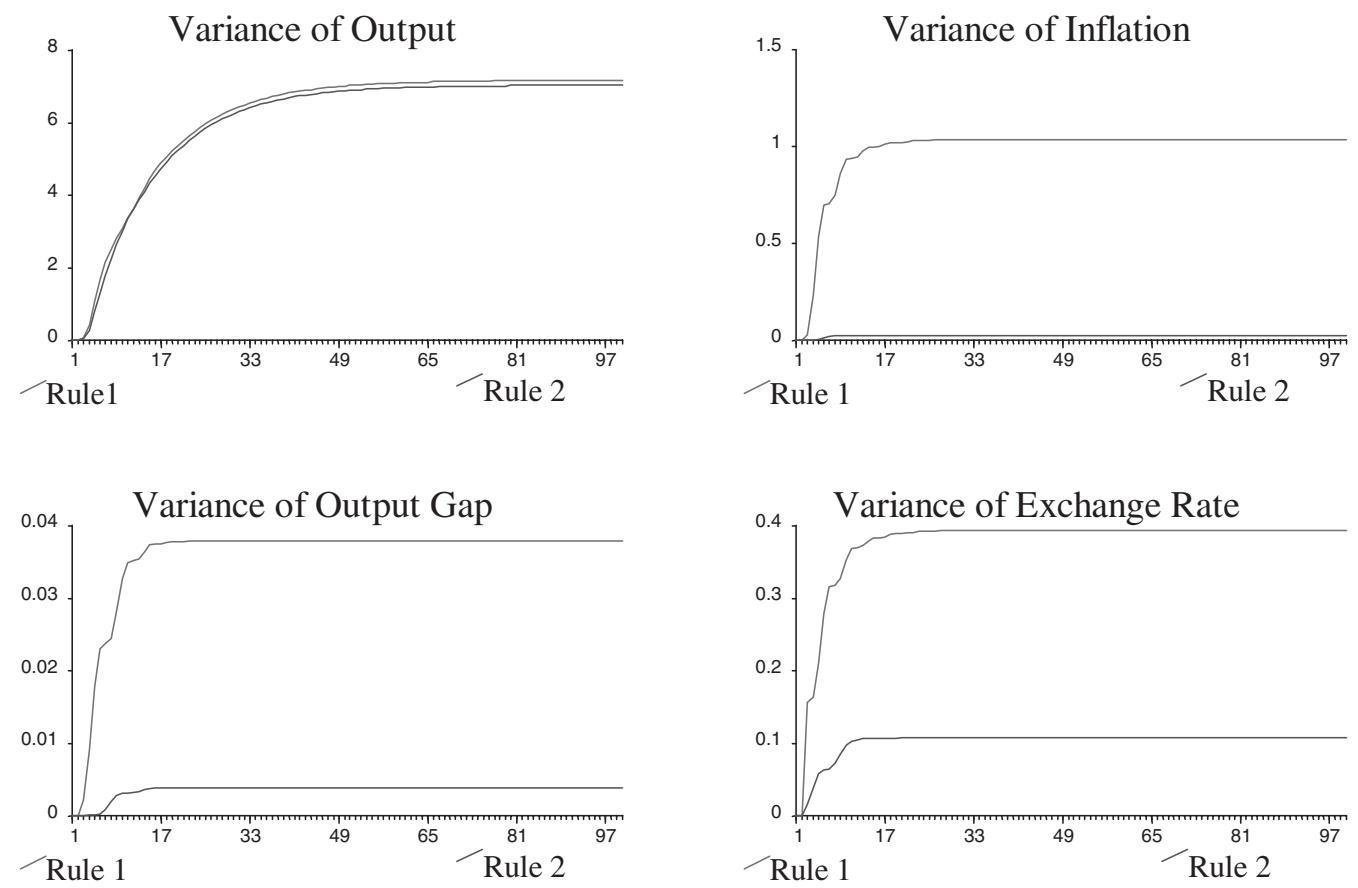

Fig. 6. Variances in response to a temporary and unanticipated $1 \%$ decrease in productivity

exchange rates on spending. This ignorance further results in unnecessarily large fluctuations in output and inflation.

The choice of MCI as an instrument for monetary policy on the other hand, enables central banks to respond to the effects of the already operating exchange rate pass-through channel. For a central bank of an open economy with flexible exchange rates and capital mobility, it is therefore advisable to include the exchange rate in the assessment 
of the monetary conditions. This applies especially to small economies, in which the exchange rate has greater significance for economic development.

Based on the simulations of the model, the results of this study show the unquestionably superiority of the MCI as a monetary policy instrument compared to the standard Taylor interest. Under all simulations conducted, the impulse responses of output, the output gap, inflation, exchange rate, interest rate, and the real exchange rate suggest that the economy stabilizes much more quickly. As evident by the volatility of the impulse response functions as well as the variances of the above variables, the economy also shows less fluctuation under the MCI rule.

Given these facts, the MCI rule should be preferable over the Taylor rule. Moreover, to alleviate the pressures caused by uncertainty in economies like Turkey, MCI should also be favoured over the Taylor interest since it induces less volatility in the economy in case of shocks. However, policymakers should also be cautious about the choice of the weights of the exchange rate and the interest rate while constructing the MCI. Since the theoretically suggested relative weights correspond to the relative size of the coefficients of the exchange rate and interest rate in the IS equation, determining the weights depends on the IS estimation. Clearly, there is no single way to estimate an IS equation. So, depending on the method used to estimate the IS equation, the relative weights may change which can also lead to drastic differences in the simulations. Yet, the results of this study remain crucial since it is an initial attempt to investigate on efficient monetary policy rules and discuss alternative ones.

\section{REFERENCES}

Ball, L. (1997) Efficient rules for monetary policy, National Bureau of Economic Research Working Paper No. 5952.

Ball, L. (1998) Policy rules for open economies, Reserve Bank of Australia, Research Discussion Paper No. 9806.

Ball, L. (1999) Policy rules for open economics, in Monetary Policy (Ed.) J. Taylor, University of Chicago Press, Chicago, pp. 127-44.

Ball, L. (2000) Policy rules and external shocks, National Bureau of Economic Research Working Paper No. 7910.

Bank of England (1999) The transmission mechanism of monetary policy, Bank of England Quarterly Bulletin, 30(2), May.

Bank of England (2000) Economic Models in the Bank of England: September 2000 Update, Bank of England, London.

Batini, N. and Haldane, A. G. (1998) Forward-looking rules for monetary policy, Bank of England Working Paper No. 91.
Batini, N. and Haldane, A. G. (1999), Monetary policy rules, in NBER Conference Volume (Ed.) J. B. Taylor, University of Chicago Press, Chicago.

Clarida, R. and Gertler, M. (1997) How the Bundesbank conducts monetary policy, National Bureau of Economic Research Working Paper No. 5581.

Clarida, R. et al. (1997) Monetary policy rules and macroeconomic stability: evidence and some theory, National Bureau of Economic Research Working Paper No. 6443.

Clarida, R., Gali, J. and Gertler, M. (1998) Monetary policy rules in practice: some international evidence, European Economic Review, 42, 1033-67.

Deutsche Bundesbank (1999) Taylor interest rate and monetary conditions index, Deutsche Bundesbank Monthly Report, April.

Freedman, C. (1994) The use of indicator and of the monetary conditions index in Canada, in Frameworks for Monetary Stability (Eds) T. J. T. Balino and C. Cottarelli, International Monetary Fund.

Freedman, C. (1995) The role of monetary conditions and the monetary conditions index in the conduct of policy, Bank of Canada Review, 1995(3), 53-9.

Gerlach, S. and Smets, F. (1996) MCIs and Monetary Policy in Small Open Economies Under Floating Exchange Rates, Bank for International Settlements.

Gerlach, S. and Smets, F. (2000) MCIs and monetary policy, European Economic Review, 44(9), 1677-700.

Hendry, D. F. (1995) Dynamic Econometrics, Oxford University Press, Oxford.

Kesriyeli, M. and Yalçın, C. (1998) Taylor Kuralı ve Türkiye Uygulaması Üzerine Bir Not, Central Bank of The Republic of Turkey, Research Department Discussion Paper No. 9802.

Kesriyeli, M. and Yalçın, C. (1998) Taylor kuralı ve Türkiye uygulaması üzerine bir not, CBRT, Research Department, Discussion Paper No. 9802.

Kesriyeli, M. and Koçaker, I. (1999) Monetary conditions index: a monetary policy indicator in Turkey, CBRT, Research Department, Discussion Paper No. 9908.

Markovic, B. (2001) Monetary transmission mechanism in UK: speeding up or slowing down, presented at the 5th ERC/ METU International Conference in Economics, Ankara, Turkey, 11 September.

Şahinbeyoğlu, G. (2001) Monetary transmission mechanism: a view from a high inflationary environment, presented at the 5th ERC/METU International Conference in Economics, Ankara, Turkey, 11 September.

Svensson, L. E. O. (1999) Inflation targeting as a monetary policy rule, Journal of Monetary Economics, 43(3), 607-54.

Svensson, L. E. O. (2000) Open-economy inflation targeting, Journal of International Economics, 50(1), 155-83.

Taylor, J. B. (1993) Discretion versus policy rules in practice, Carnegie-Rochester Conference Series on Public Policy, 39, pp. 195-214. 